\title{
Validation of Np-237 cross sections by analysis of BFS critical experiments with massively neptunium-loaded cores
}

\author{
M. Ishikawa ${ }^{\mathrm{a}}$ and T. Hazama ${ }^{\mathrm{b}}$ \\ Japan Atomic Energy Agency (JAEA), Ibaraki 311-1393, Japan
}

\begin{abstract}
Three series of BFS critical experiments loaded approximately with $10 \mathrm{~kg}$ of ${ }^{237} \mathrm{~Np}$-dioxide were analyzed to verify the performance of major libraries with the ${ }^{237} \mathrm{~Np}$ nuclear data. The latest JENDL-3.3, ENDF/B-VII.0 and JEFF-3.1 showed satisfactory results from the ${ }^{237} \mathrm{~Np}$ data viewpoint; however some other major data such as ${ }^{239} \mathrm{Pu}$ $v$ and fission, ${ }^{238} \mathrm{U} \mu$ and/or the sodium inelastic scattering cross sections of some libraries may need re-evaluation. Further, the effect of integral experimental information to obtain better predictions of reactor core parameters was demonstrated by the cross section adjustment method.
\end{abstract}

\section{Introduction}

In the nuclear fuel cycle of the future, the minor actinides (MA) in spent fuel should be recycled and utilized as valuable fuel materials to generate electricity, rather than disposed as harmful waste to be buried deeply underground. The composition of MA from light water reactor spent fuel is estimated as ${ }^{237} \mathrm{~Np} /{ }^{241} \mathrm{Am} /{ }^{243} \mathrm{Am} /{ }^{244} \mathrm{Cm}=49 / 30 / 16 / 5$ (\%) under the conditions of $35 \mathrm{GWd} / \mathrm{t}$ burn-up and a 5-year cooling period before reprocessing. The isotope found in the largest amount in LWR-originated MA, ${ }^{237} \mathrm{~Np}$, is a type of fertile material, and the influences thereof on the fast reactor core nuclear characteristics is much stronger than that of the same amount of ${ }^{238} \mathrm{U}$. Generally speaking, there are two aspects to the loading of ${ }^{237} \mathrm{~Np}$ into fast reactor cores. From the viewpoint of safety, the massive ${ }^{237} \mathrm{~Np}$ loading is not preferable because sodium void reactivity will increase positively, control rod worth will decrease, and the absolute value of Doppler reactivity will decrease, the reason for which being the neutron spectrum hardening due to the large capture cross section of ${ }^{237} \mathrm{~Np}$ in the middle energy region and threshold fission cross section in the high energy region. On the other hand, from the viewpoint of economics, the ${ }^{237} \mathrm{~Np}$ loading has the advantage that the potential for a long-life core without refuelling is increased by the decrease of burn-up reactivity loss due to the generation of the semi-fissile isotope ${ }^{238} \mathrm{Pu}$ from the effective capture reaction of ${ }^{237} \mathrm{~Np}$.

In the field of reactor physics, it is almost indispensable for realistic design work and licensing permission to make integral critical experiments with un-experienced material which is planned for new introduction into the reactor core. In regard to ${ }^{237} \mathrm{~Np}$, only the BFS facility in IPPE, Russia possesses a large amount required $\left(10 \mathrm{~kg}\right.$ of ${ }^{237} \mathrm{~Np}$-dioxide pellets), and the ability to perform massively ${ }^{237} \mathrm{~Np}$-loaded core critical experiments. The intrinsic feature of a massive target-material loading critical experiment is to measure various core parameters in the neutron field which are strongly influenced by the target-material. This is not possible by

\footnotetext{
a e-mail: ishikawa.makoto@jaea.go.jp

$b$ e-mail: hazama.taira@jaea.go.jp, Present address: Saclay, CEA, France
}

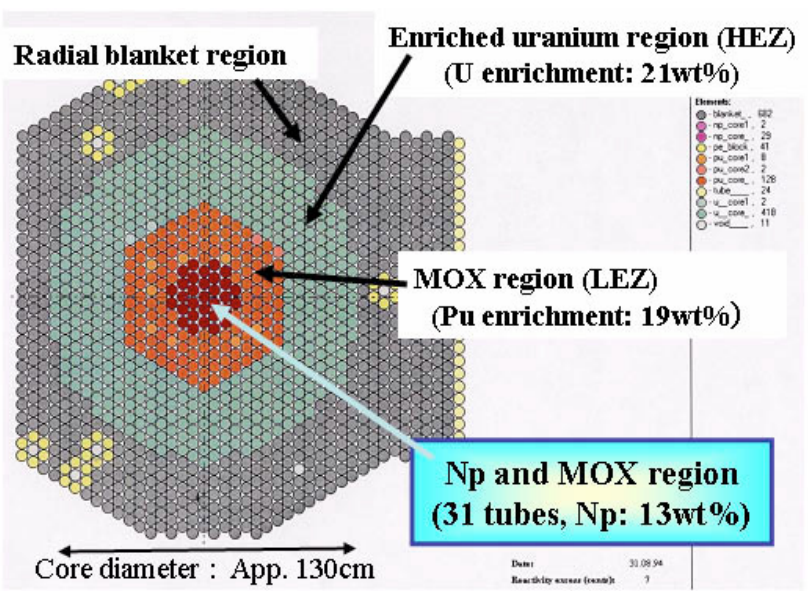

Fig. 1. Horizontal plain of BFS-67-2R core with ${ }^{237} \mathrm{~Np}$ loading in the core centre region ( $\mathrm{Np}$ and MOX test region: $15 \mathrm{~cm}$ radius by $38 \mathrm{~cm}$ height).

sample foil irradiation or sample worth measurement. JAEA entered into a cooperative contract with IPPE, and obtained asbuilt information on three series of ${ }^{237} \mathrm{~Np}$-loaded experiments, which is necessary for the most-detailed level of analysis and quantitative evaluation.

The objectives of the present study are to verify the ${ }^{237} \mathrm{~Np}$ nuclear data of major libraries and demonstrate the use of integral experimental information for better predictions of reactor core parameters.

\section{Description of Np-loaded BFS experiments}

The features of three series of ${ }^{237} \mathrm{~Np}$-loaded experiments are as follows: (1) BFS-67 series: Standard fast reactor cores (Pu enrichment in total heavy metal mass: app. $19 \mathrm{wt} \%,{ }^{240} \mathrm{Pu}$ ratio in total Pu: app. 4\%) in refs. [1,2], (2) BFS-69 series: Fast reactor cores for efficient $\mathrm{Pu}$ burning ( $\mathrm{Pu}$ enrichment: app. $40 \mathrm{wt} \%$ ), and (3) BFS-66-2 series: Fast reactor cores with degraded $\mathrm{Pu}$ (Pu-240 ratio: app. 10\%). BFS-67 and 69 series experiments were performed in the BFS-1 facility, and 


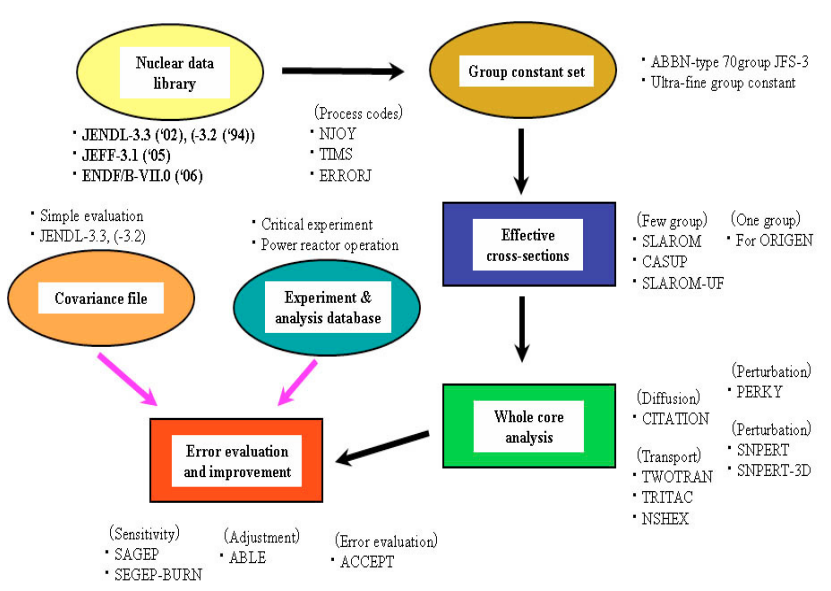

Fig. 2. Analytical flow and related codes applied to the analysis of Np-loaded BFS experiments.

BFS-66-2 series experiments in BFS-2. Both facilities used common fuel pellets. In each series, the reference experiment without ${ }^{237} \mathrm{~Np}$ and the next the massively ${ }^{237} \mathrm{~Np}$-loaded experiment were performed by replacing ${ }^{238} \mathrm{U}$ pellets with ${ }^{237} \mathrm{~Np}$ pellets in the central test region. Figure 1 shows an example of ${ }^{237} \mathrm{~Np}$-loaded BFS core, BFS-67-2R.

\section{Analyses of Np-loaded BFS experiments by major libraries}

The libraries used in the present study are the JENDL3.3 ('02), JEFF-3.1('05), ENDF/B-VII.0('06) and JENDL-3.2 ('94). The analytical methodology applied to these Np-loaded core experiments is based on the most-detailed level of deterministic code system developed in Japan, which is described in ref. [3]. Figure 2 shows the analytical flow applied here. The main features of analysis are: 1) a 70-group ABBN-type constant set as the basic nuclear data, 2) cell heterogeneity treatment based on the collision probability, 3) cell streaming modelling by the Benoist's anisotropic diffusion coefficient, 4) three-dimensional whole core diffusion calculation, 5) correction by neutron transport theory and mesh-size effect, and 6) correction by fine group calculation with the app. 100,000 group below $50 \mathrm{keV}$ and the 175 group above $50 \mathrm{keV}$.

\subsection{Selection of core parameters}

Although a variety of core parameters were measured in the Np-loaded core BFS experiments, it was initially essential to find meaningful parameters with which to verify ${ }^{237} \mathrm{~Np}$ nuclear data. Since the test region replacing ${ }^{238} \mathrm{U}$ with ${ }^{237} \mathrm{~Np}$ comprises only local central parts of the core as described in section 2, whole-core characteristics such as criticality are of no value for this objective. A sensitivity analysis based on generalized perturbation theory was applied, and the useful core parameters were found to be the sodium void reactivity of the test region and the central control rod worth height which is almost the same as in the test region. Figure 3 shows a sample of the sensitivity of sodium void reactivity to cross sections.

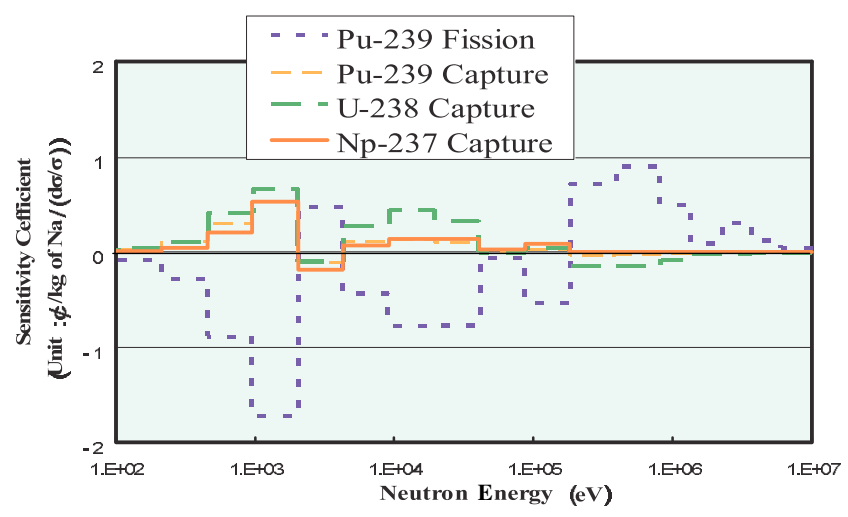

Fig. 3. Cross section sensitivity coefficients of sodium void reactivity in BFS-67-2R core with ${ }^{237} \mathrm{~Np}$ loading.

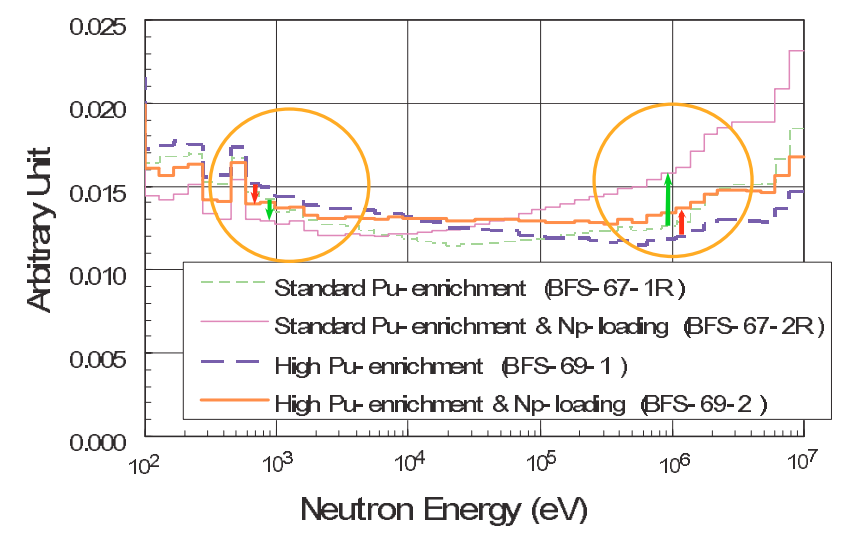

Fig. 4. Changes of the adjoint flux energy-shape by ${ }^{237} \mathrm{~Np}$ loading.

\subsection{Effect of ${ }^{237} \mathrm{~Np}$ loading to the adjoint flux}

As mentioned in section 1 , the nature of ${ }^{237} \mathrm{~Np}$ cross section strongly affects certain reactivity such as sodium void worth through the energy-shape changing of the adjoint flux. In figure 4 , the analytical results of the adjoint flux changes are demonstrated for the BFS-67 and BFS-69 series. By ${ }^{237} \mathrm{~Np}$ loading, the adjoint flux is definitely flattened in the middle energy region. On the other hand, it becomes steep in the high energy region.

\subsection{Analytical results by major libraries}

Table 1 summarizes the experimental values and analytical results of sodium void reactivity in the test region with and without ${ }^{237} \mathrm{~Np}$ loading for the three BFS experimental series. As is seen, all experimental values of sodium void reactivity shift to the positive direction by loading ${ }^{237} \mathrm{~Np}$ in spite of the $\mathrm{Pu}$ enrichment differences, the ${ }^{240} \mathrm{Pu}$ ratio in total $\mathrm{Pu}$, or whether the experiments were performed at the BFS-1 or BFS-2 facility. The results of BFS-69 series are especially interesting. Because of the soft neutron spectrum caused by the large volume ratio of coolant and structural material, 
Table 1. Analytical results of sodium void reactivity for three series of massively ${ }^{237} \mathrm{~Np}$-loaded BFS experiments.

\begin{tabular}{|c|c|c|c|c|}
\hline Core & ${ }^{237} \mathrm{~Np}$ & $\begin{array}{l}\text { Exp. value } \\
\text { (cents) }\end{array}$ & Library & $\begin{array}{l}\text { C-E } \\
\text { (cents) }\end{array}$ \\
\hline \multirow{4}{*}{ BFS- } & \multirow{4}{*}{ No } & \multirow{4}{*}{$\begin{array}{l}\mathbf{+ 6 . 2} \\
\text { (Exp. error: } \\
\pm 0.3 \text { ) }\end{array}$} & JENDL-3.3 & -1.5 \\
\hline & & & JEFF-3.1 & -1.3 \\
\hline & & & ENDF-7.0 & -1.8 \\
\hline & & & JENDL-3.2 & -1.4 \\
\hline \multirow{4}{*}{ BFS- } & \multirow{4}{*}{ Yes } & \multirow{4}{*}{$\begin{array}{l}\mathbf{+ 1 8 . 8} \\
\text { (Exp. error: } \\
\pm 0.8)\end{array}$} & JENDL-3.3 & -2.0 \\
\hline & & & JEFF-3.1 & -2.2 \\
\hline & & & ENDF-7.0 & -3.2 \\
\hline & & & JENDL-3.2 & -2.2 \\
\hline \multirow{4}{*}{ BFS- } & \multirow{4}{*}{ No } & \multirow{4}{*}{$\begin{array}{l}\mathbf{- 3 5 . 6} \\
\text { (Exp. error: } \\
\pm 1.0 \text { ) }\end{array}$} & JENDL-3.3 & +2.0 \\
\hline & & & JEFF-3.1 & -5.7 \\
\hline & & & ENDF-7.0 & +2.1 \\
\hline & & & JENDL-3.2 & +2.9 \\
\hline \multirow{4}{*}{ BFS- } & \multirow{4}{*}{ Yes } & \multirow{4}{*}{$\begin{array}{l}\mathbf{- 5 . 0} \\
\text { (Exp. error: } \\
\pm 1.5 \text { ) }\end{array}$} & JENDL-3.3 & +7.8 \\
\hline & & & JEFF-3.1 & +11.5 \\
\hline & & & ENDF-7.0 & +3.4 \\
\hline & & & JENDL-3.2 & +8.4 \\
\hline \multirow{4}{*}{ BFS- } & \multirow{4}{*}{ No } & \multirow{4}{*}{$\begin{array}{l}\mathbf{+ 7 . 1} \\
\text { (Exp. error: } \\
\pm 0.3 \text { ) }\end{array}$} & JENDL-3.3 & -2.5 \\
\hline & & & JEFF-3.1 & -2.2 \\
\hline & & & ENDF-7.0 & -3.2 \\
\hline & & & JENDL-3.2 & -2.3 \\
\hline \multirow{4}{*}{ BFS- } & \multirow{4}{*}{ Yes } & \multirow{4}{*}{$\begin{array}{l}\mathbf{+ 1 2 . 1} \\
\text { (Exp. error: } \\
\pm 0.3 \text { ) }\end{array}$} & JENDL-3.3 & +0.5 \\
\hline & & & JEFF-3.1 & -0.1 \\
\hline & & & ENDF-7.0 & -0.5 \\
\hline & & & JENDL-3.2 & +0.2 \\
\hline
\end{tabular}

sodium void reactivity was negative, as is understandable from flattened adjoint spectrum in figure 4 ; however, it continued to move toward the positive direction by ${ }^{237} \mathrm{~Np}$ loading.

In table 1, the analytical results of the major libraries are expressed as the absolute reactivity differences between calculation $(\mathrm{C})$ and experiment $(\mathrm{E})$ in the unit of cents. Generally speaking, all four libraries show quite good performances of ${ }^{237} \mathrm{~Np}$ loading effect for sodium void reactivity.

However, when we investigate these results in detail, there appear some curious points. The most curious of these occurs in for the BFS-69 series, high Pu-enrichment cases. Although the ${ }^{237} \mathrm{~Np}$ data of JEFF-3.1 was imported from JENDL-3.3, the analytical results of the ${ }^{237} \mathrm{~Np}$-loading effect are significantly different. ENDF/B-VII.0 also shows behaviours independent from the others. To find the reason for this, a sensitivity survey was performed to analyze nuclide- and reaction-wise contributions. The differences of JEFF-3.1 and ENDF/B-VII.0 from JENDL-3.3 for the sodium void reactivity of BFS69 without and with ${ }^{237} \mathrm{~Np}$-loading are shown in figure 5 with nuclide and reaction breakdowns. The first thing to be noticed from figure 5 is that the difference from ${ }^{237} \mathrm{~Np}$ data between ENDF and JENDL is negligible. The second fact to be emphasized is that the general agreement of sodium void reactivity analysis among these major libraries is only a result of accidental cancellation due to several nuclide/reaction differences such as ${ }^{239} \mathrm{Pu} v$ and fission, ${ }^{238} \mathrm{U} \mu$ and/or sodium inelastic scattering cross sections. From the present study, it is difficult to judge which library is good or bad, however, it

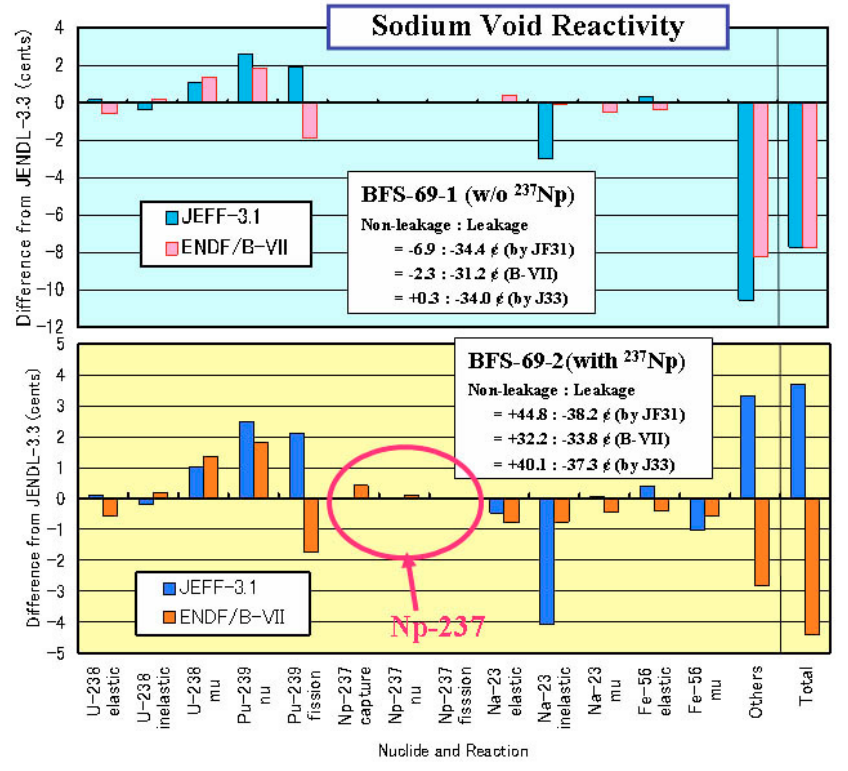

Fig. 5. Nuclide- and reaction-wise contribution to differences of sodium void reactivity of BFS-69 series by major libraries.

could be said that some libraries need to be re-evaluated for the above-mentioned nuclide/reactions.

\section{Improvement of prediction accuracy for $\mathrm{Np}$-loaded cores by use of integral information}

In order to improve the prediction accuracy of nuclear characteristics, the most rational and efficient method is to adjust the cross sections based on the Bayesian theory and leastsquare technique, where all related information including $\mathrm{C} / \mathrm{E}$ values, experimental and analytical errors, sensitivity coefficients of various experimental cores and parameters, and cross section covariance, are synthesized with physical consistency. The detailed methodology of the cross section adjustment adopted here is reported in ref. [4]. The basic pre-adjustment library before applied here is JENDL-3.2 and its covariance data, but ${ }^{237} \mathrm{~Np}$ data was adopted from JENDL-3.3, since there is no covariance data of ${ }^{237} \mathrm{~Np}$ in JENDL-3.2.

To measure the effect of the ${ }^{237} \mathrm{~Np}$-loaded core experiments, we compare two cases of the adjustment, A and B. Case $\mathrm{A}$ is a cross section adjustment with the $233 \mathrm{C} / \mathrm{E}$ values and their errors without the ${ }^{237} \mathrm{~Np}$ data of BFS, and Case B is that with $239 \mathrm{C} / \mathrm{E}$ values and their errors with ${ }^{237} \mathrm{~Np}$ data, where the BFS experimental error and analytical modelling error were estimated as follows: for sodium void reactivity, app. $\pm 4 \%$ and app. $\pm 3 \%$, and for central control rod worth, app. $\pm 6 \%$ and app. $\pm 1 \%$, respectively.

Table 2 summarizes the $\mathrm{C} / \mathrm{E}$ values and their cross sectioninduced errors, before and after adjustment, for sodium void reactivity and central control rode worth of BFS-67-2R core with ${ }^{237} \mathrm{~Np}$-loading in the test region. The cross section induced errors are calculated by multiplying sensitivity vector by covariance matrix. Clear error reduction after adjustment is found, especially for sodium void reactivity. 
Table 2. C/E values and their cross section induced errors of sodium void reactivity and central control rod worth for BFS-67 series experiments with ${ }^{237} \mathrm{~Np}$-loading.

\begin{tabular}{|c|c|c|c|c|c|c|}
\hline \multirow{2}{*}{$\begin{array}{l}\text { Core } \\
\text { Parameters } \\
\text { measured in } \\
\text { Np-loaded } \\
\text { BFS core }\end{array}$} & \multirow{2}{*}{\multicolumn{2}{|c|}{$\begin{array}{l}\text { Before } \\
\text { adjustment }\end{array}$}} & \multicolumn{4}{|c|}{ After adjustment } \\
\hline & & & $\begin{array}{r}\mathbf{C} \\
(233 \\
\mathrm{Np} \\
\end{array}$ & $\begin{array}{l}\text { e A } \\
\text { Es w/o } \\
\text { paded } \\
\text { data) }\end{array}$ & $\begin{array}{r}\mathbf{C} \\
(239 \\
\mathrm{Np}\end{array}$ & $\begin{array}{l}\text { se B } \\
\text { Es with } \\
\text { oaded } \\
\text { data) }\end{array}$ \\
\hline & $\mathrm{C} / \mathrm{E}$ & Error & $\mathrm{C} / \mathrm{E}$ & Error & $\mathrm{C} / \mathrm{E}$ & Error \\
\hline $\begin{array}{l}\text { Sodium void } \\
\text { reactivity } \\
\text { (BFS-67-2R) }\end{array}$ & 0.885 & $\begin{array}{l}5.5 \\
\%\end{array}$ & 0.907 & $\begin{array}{l}2.5 \\
\%\end{array}$ & 0.915 & $\begin{array}{l}2.0 \\
\%\end{array}$ \\
\hline $\begin{array}{l}\text { Control rod } \\
\text { worth } \\
\text { (BFS-67-2R) }\end{array}$ & 0.958 & $\begin{array}{l}2.6 \\
\%\end{array}$ & 0.932 & $\begin{array}{l}\mathbf{1 . 0 _ { 4 }} \\
\%\end{array}$ & 0.945 & $\begin{array}{l}\mathbf{0 . 9} \\
\%\end{array}$ \\
\hline
\end{tabular}

* "Error" is one sigma value of cross section-induced error.

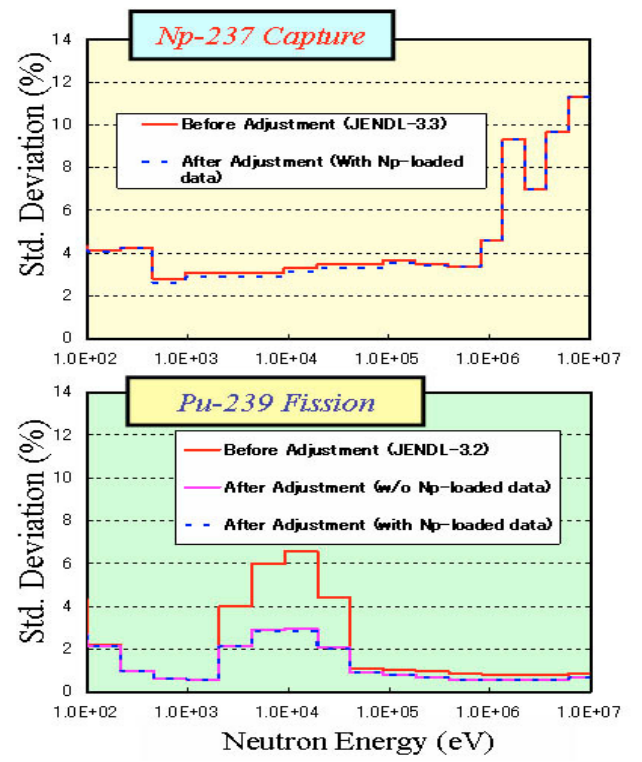

Fig. 6. Change of standard deviations of the ${ }^{237} \mathrm{~Np}$ capture and ${ }^{239} \mathrm{Pu}$ fission cross sections before and after adjustment with and without ${ }^{237} \mathrm{~Np}$-loading BFS data.

Next, we surveyed the mechanism of the error reduction for these core parameters of the ${ }^{237} \mathrm{~Np}$-loaded core. Figure 6 shows the changes of the standard deviation by cross section adjustment for the ${ }^{237} \mathrm{~Np}$ capture and ${ }^{239} \mathrm{Pu}$ fission reaction which has a large sensitivity for the sodium void reactivity. There is no difference between with and without ${ }^{237} \mathrm{~Np}$ experimental data.

Actually, the error reduction of the cross section-induced error was caused by the important nuclides and reactions are strongly correlated after adjustment as shown in figure 7 .

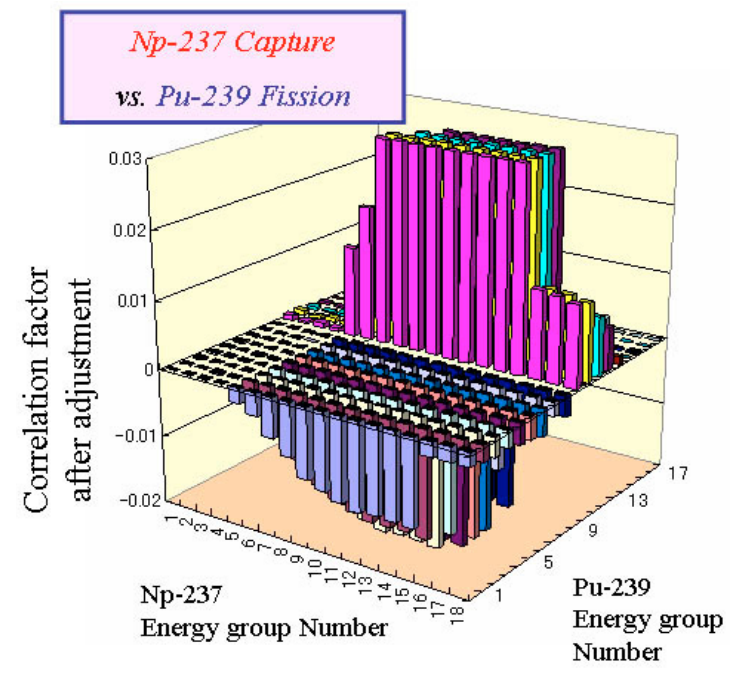

Fig. 7. Correlation factors between the ${ }^{237} \mathrm{~Np}$ capture and ${ }^{239} \mathrm{Pu}$ fission cross sections after adjustment with ${ }^{237} \mathrm{~Np}$-loading BFS data.

\section{Conclusions}

The latest JENDL-3.3, ENDF/B-VII.0 and JEFF-3.1 showed satisfactory results from a ${ }^{237} \mathrm{~Np}$ data viewpoint, but some other major data such as ${ }^{239} \mathrm{Pu} v$ and fission, ${ }^{238} \mathrm{U} \mu$ and/or sodium inelastic scattering cross sections of some libraries may need re-evaluation. Also, the use of integral experimental information for better prediction of reactor core parameters is demonstrated.

Authors appreciate the sincere efforts of the IPPE staff, Dr A. Kochetkov, Dr I. Matveenko and Dr A. Tsiboulia for providing us the exact as-built information on the Np-loaded BFS experiments under the cooperative contract between IPPE and JNC (the former JAEA).

\section{References}

1. S.B. Belov et al., Experimental Investigations of Fast Reactor Core Characteristics with Neptunium in Fuel at the BFS-1 Critical Facility, in Proceedings of the 9th Topical Meeting on Problems of Nuclear Reactor Safety, Moscow, Sept. 4-8, 1995.

2. S.P. Belov, G. Rimpault et al., Investigation of MA Transmutation Problem in Benchmark Experiments at BFS Facility with Neptunium in Fuel Composition, in Proceedings of Int. Conf. on the Physics of Reactors (PHYSOR 96), Mito, Sept. 16-20, 1996.

3. M. Ishikawa, Recent Application of Nuclear Data to Fast Reactor Core Analysis and Design in Japan, in Proceedings of Int. Conf. on Nuclear Data for Science and Technology (ND2004), Santa Fe, Sept. 26-Oct. 1, 2004.

4. M. Ishikawa, et al., Development of a Unified Cross-section Set ADJ2000 based on Adjustment Technique for Fast Reactor Analysis, in Proceedings of Int. Conf. on Nuclear Data for Science and Technology (ND2001), Tsukuba, Oct. 7-12, 2001. 